\title{
Role of Ouabain-like Compound in the Rostral Ventrolateral Medulla in Rats
}

\author{
Hiroshi Teruya, ${ }^{*}$ Masanobu Yamazato, ${ }^{*}$ Hiromi Muratani, ${ }^{*}$ Atsushi Sakima, ${ }^{*}$ Shuichi Takishita, ${ }^{*}$ Yoshitake Terano, ${ }^{\ddagger}$ \\ and Koshiro Fukiyama* \\ *Third Department of Internal Medicine, University of the Ryukyus School of Medicine, Okinawa 903-01, Japan; and ${ }^{\ddagger}$ The Second \\ Department of Physiology, Osaka City University Medical School, Osaka 545, Japan
}

\begin{abstract}
To determine whether ouabain-like compound (OLC) exerts modulatory influences on the activity of vasomotor neurons in the rostral ventrolateral medulla (RVLM), we examined the effects of microinjecting ouabain, digoxin-specific antibody Fab fragments, and mAb against ouabain on the rat RVLM. Microinjection of ouabain into the unilateral RVLM of anesthetized normotensive rats elicited dose-dependent increases in mean arterial pressure (MAP) and renal sympathetic nerve activity (RSNA). The pressor and sympathoexcitatory effects of ouabain in the RVLM were reversed by microinjections of an $M_{2}$ muscarinic antagonist, gallamine, or digoxin-specific antibody Fab fragments. Furthermore, a prior microinjection in the RVLM of gallamine, digoxinspecific antibody Fab fragments, or kainic acid or intravenous injection of hexamethonium all prevented the pressor and sympathoexcitatory effects induced by a subsequent microinjection of ouabain. Microinjections of either digoxinspecific antibody Fab fragments or gallamine per se significantly decreased baseline MAP and RSNA. Injection of digoxin-specific antibody Fab fragments attenuated the effects of a subsequent injection of gallamine. Microinjection of $\mathrm{mAb}$ against ouabain, but not nonspecific IgG, also significantly decreased baseline MAP and RSNA. These results suggest that OLC in the RVLM contributes to the tonic activity of vasomotor neurons in anesthetized normotensive rats, and the action of OLC in the RVLM is at least partly mediated by $\mathrm{M}_{2}$ muscarinic mechanisms. (J. Clin. Invest. 1997. 99:2791-2798.) Key words: $\mathrm{Na}^{+}, \mathrm{K}^{+}$-ATPase $\bullet$ blood pressure - sympathetic nervous system - muscarinic receptors $\bullet$ microinjections
\end{abstract}

\section{Introduction}

$\mathrm{Na}^{+}, \mathrm{K}^{+}$-ATPase is ubiquitously distributed in all cells for the maintenance of cellular homeostasis. In excitable tissues, espe-

\footnotetext{
Part of this study was presented at the 18th Annual Meeting of the Japanese Society of Hypertension, Tokyo, Japan, in October 1995, and has appeared in abstract form (1995. Hypertens. Res. 18:331).

Address correspondence to Hiroshi Teruya, M.D., Third Department of Internal Medicine, University of the Ryukyus School of Medicine, 207 Uehara, Nishihara-cho, Okinawa 903-01, Japan. Phone: 8198-895-3331; FAX: 81-98-895-2702; E-mail: sannai@med.u-ryukyu. ac.jp S. Takishita's current address is Division of Hypertension and Nephrology, National Cardiovascular Center, 5-7-1, Fujishirodai, Suita, Osaka 565, Japan.

Received for publication 1 May 1996 and accepted in revised form 13 March 1997.
}

J. Clin. Invest.

(C) The American Society for Clinical Investigation, Inc.

0021-9738/97/06/2791/08 \$2.00

Volume 99, Number 11, June 1997, 2791-2798 cially in the nervous system, $\mathrm{Na}^{+}, \mathrm{K}^{+}$-ATPase activity is essential for the regulation of membrane potential and is responsible for cell excitability and neurotransmitter release. Evidence suggests that endogenous digitalis-like inhibitors of $\mathrm{Na}^{+}, \mathrm{K}^{+}$ATPase exist in the plasma, urine, and/or tissue of different mammalian species, including humans, and contribute to the regulation of $\mathrm{Na}^{+}, \mathrm{K}^{+}$-ATPase activity and the pathogenesis of volume-dependent hypertension (1-3). Ludens et al. (4) reported that an endogenous digitalis-like factor purified from human plasma was plant ouabain or its stereoisomer (ouabainlike compound, OLC). ${ }^{1}$ It was subsequently confirmed that the human plasma OLC and bovine hypothalamic $\mathrm{Na}^{+}, \mathrm{K}^{+}-$ ATPase inhibitors were structurally identical substances which closely resembled ouabain $(5,6)$. Thus OLC is a strong candidate for a putative digitalis-like inhibitor. However, its physiological roles still remain to be elucidated.

The hypertensinogenic actions of OLC are thought to be mediated by effects on cardiovascular structure (7-9) and the sympathetic nervous system (10). In spontaneously hypertensive rats (11) and Dahl salt-sensitive rats (12), the central nervous system seems to be the site where the OLC exerts its hypertensinogenic effects. In support of this view, Takahashi et al. demonstrated by using mAb against ouabain (named T8B11) that ouabain-like immunoreactive substances predominantly exist in the paraventricular nucleus of the rat hypothalamus (13). Using the antibody, we noticed the existence of ouabain-like immunoreactivities in the rostral ventrolateral medulla (RVLM) of rats (14). The RVLM neurons are critical for the central regulation of sympathetic activity (15-17). Acetylcholine plays a major role in the regulation of the tonic activity of the RVLM neurons via $\mathrm{M}_{2}$ muscarinic receptors, and the RVLM may be the central hypertensive site for these cholinergic mechanisms $(18,19)$. Furthermore, ouabain induces acetylcholine release from brain cholinergic synaptosomes in vitro (20-22). Thus, we hypothesize that the OLC contributes to the tonic activity of RVLM neurons via cholinergic mechanisms. In this study, we examined the effects of ouabain, digoxin-specific antibody Fab fragments (Digibind; Burroughs Wellcome and Co., London, United Kingdom), and mAb T8B11 microinjected into the RVLM of anesthetized normotensive rats.

\section{Methods}

Animals. Male Sprague-Dawley rats were purchased from Charles River Japan, Inc. and fed standard laboratory rat chow and tap water ad libitum. All of the procedures were in accordance with the National Institutes of Health guidelines for the care and use of laboratory animals. The protocol was approved by the Animal Care and Use Committee of the University of the Ryukyus.

1. Abbreviations used in this paper: CSF, cerebrospinal fluid; L-Glu, L-glutamate; MAP, mean arterial pressure; OLC, ouabain-like compound; RSNA, renal sympathetic nerve activity; RVLM, rostal ventrolateral medulla. 
Animal preparation. At 7-8 wk of age, rats (240-340 g) were anesthetized with intraperitoneal injections of $1.3 \mathrm{~g} / \mathrm{kg}$ of urethane. Body temperatures were kept within $37 \pm 1^{\circ} \mathrm{C}$ using a heating pad. The femoral artery and veins were cannulated for the measurement of arterial pressure and the administration of drugs, respectively. Rats were fixed on a stereotaxic frame (Narishige Scientific Instruments, Tokyo, Japan) in a supine position. The distal trachea was cannulated and connected to a ventilator (model 683; Harvard Apparatus Inc., South Natick, MA). Arterial blood gases and $\mathrm{pH}$ were kept within normal limits by artificial ventilation. Then the left kidney was exposed via a transperitoneal approach. A branch of the renal nerves was placed on a bipolar silver wire electrode (7855; A-M Systems, Inc., Everett, WA). The nerve and the electrode were embedded in silicone gel (Sil-Gel 604; Wacker Siltronic GmbH, Munich, Germany). The original renal nerve signals were amplified and filtered between 30 and 1,000 Hz (DPA-100E; Dia Medical System, Tokyo, Japan). The amplified nerve pulses were counted with a spikecounter (DSE-325A; Dia Medical System). At the end of each experiment, $40 \mathrm{mg} / \mathrm{kg}$ of hexamethonium was intravenously injected to evaluate the amount of background noise during renal sympathetic nerve activity (RSNA) measurements. The baseline value of RSNA (spikes/s) in each rat was designated as $100 \%$, and changes in RSNA were expressed as a percentage of the resting value ( $\% \Delta$ RSNA).

Microinjection procedure. Multibarrel glass micropipettes with tip diameters of $20-50 \mu \mathrm{m}$ were used for microinjections. The inner surface was coated with silicone (Sigmacote; Sigma Chemical Co., St. Louis, MO). After the ventral surface of the medulla oblongata was exposed, the RVLM was identified by an unilateral injection of $2 \mathrm{nmol}$ of L-glutamate (L-Glu) based on the modified criteria outlined in our previous studies (23) as follows: $(a)$ the latency of the onset of changes in BP produced by L-Glu was no more than $5 \mathrm{~s}$; $(b)$ the response plateau occurred within $20 \mathrm{~s}$ after the microinjection of L-Glu; and $(c)$ the change in mean arterial pressure (MAP) was at least 25 $\mathrm{mmHg}$. The RVLM was located $0.6-0.8 \mathrm{~mm}$ ahead of the most rostral rootlet of the hypoglossal nerve, $1.8-1.9 \mathrm{~mm}$ lateral to the midline, and $0.6-0.8 \mathrm{~mm}$ below the ventral surface. The preparation and microinjection procedures have been described in detail elsewhere (24).

Drug administration. Drugs other than immunoglobulins were all dissolved in artificial cerebrospinal fluid (CSF) $(133.3 \mathrm{mmol} / \mathrm{liter}$ sodium chloride, $3.4 \mathrm{mmol} /$ liter potassium chloride, $1.3 \mathrm{mmol} / \mathrm{liter}$ calcium chloride, $1.2 \mathrm{mmol} /$ liter magnesium chloride, $0.6 \mathrm{mmol} /$ liter sodium dihydrogen orthophosphate, $32.0 \mathrm{mmol} /$ liter sodium bicarbonate, and $3.4 \mathrm{mmol} /$ liter glucose). Immunoglobulins such as the Fab fragments, mAb T8B11, and nonspecific IgG were dissolved in distilled water to maintain isotonicity. Drugs were microinjected unilaterally into the RVLM over a 30 -s period. The injection volume was 50 nl. The volume was measured by observing the fluid meniscus through a microscope equipped with a reticule. All experimental protocols were performed in separate groups of rats, except that artificial $\mathrm{CSF}$ of control vehicle was injected in the same rat. Pretreatments by some drugs in the RVLM were performed 5 min before microinjection of later drugs except for pretreatment by the Fab fragments, which was performed 15 min before because plateau response attained by microinjection of the Fab fragments needed $12 \mathrm{~min}$ in contrast to $3 \mathrm{~min}$ by that of ouabain. Drugs were microinjected once except for mAb T8B11, which was microinjected twice. In experiments testing effects of ouabain or digoxin-specific antibody Fab fragments, $5 \mathrm{nl}$ of an emulsion of Alcian blue dye was injected from a separate barrel of the multibarrel pipette to mark the site of injection.

Inhibition of $\mathrm{Na}^{+}, \mathrm{K}^{+}$-ATPase in the RVLM. The effects of microinjecting 1,10 , and $100 \mathrm{ng}$ of ouabain into the RVLM were examined. The effects of nonspecific inhibition of $\mathrm{Na}^{+}, \mathrm{K}^{+}$-ATPase in the RVLM were also examined by microinjection of $0.05 \mathrm{nmol}$ of melittin, a nonspecific inhibitor of $\mathrm{Na}^{+}, \mathrm{K}^{+}$-ATPase. The effects of ouabain on MAP were also examined after ganglionic blockade by intravenous injection of $40 \mathrm{mg} / \mathrm{kg}$ of hexamethonium. In this setting, baseline MAP was maintained by intravenous infusion of phenylephrine. Furthermore, to exclude the possibility that ouabain acts on the nerve fibers in the passage in the RVLM, 10 ng of ouabain was microinjected 5 min after local pretreatment with $1 \mathrm{nmol}$ of kainic acid, an effective cell body neurotoxin (25). In a preliminary experiment using three rats, the pressor and sympathoexcitatory responses to microinjection of L-Glu into the RVLM were completely abolished $5 \mathrm{~min}$ after local pretreatment with kainic acid.

Prevention and reversal of the effects of exogenously administered ouabain by an $M_{2}$ muscarinic antagonist or digoxin-specific antibody Fab fragments. In a preliminary study, a prior injection of $2 \mathrm{nmol}$ of atropine into the RVLM attenuated the subsequent response to microinjection of $10 \mathrm{ng}$ of ouabain compared with artificial CSF pretreatment ( $\Delta$ MAP: $5 \pm 2$ vs. $14 \pm 1 \mathrm{mmHg}, \% \Delta$ RSNA: $10 \pm 3$ vs. $53 \pm 11 \%$, $P<0.01, n=7)$. The digoxin-specific antibody Fab fragments are reported to neutralize ouabain or the digitalis-like factor obtained from umbilical cord blood (26), and to block the central effects of ouabain or rat hypothalamo-pituitary extracts containing OLC (27). Therefore, we examined whether microinjection of $2 \mathrm{nmol}$ of gallamine (an $\mathrm{M}_{2}$ muscarinic antagonist (28)) or $0.75 \mu \mathrm{g}$ of the Fab fragments could prevent or reverse the effects of exogenous ouabain in the RVLM. The dosage of the Fab fragments was chosen to neutralize (26) or block the effects of $10 \mathrm{ng}$ of ouabain (27).

Effects of blocking the OLC in the RVLM, and interaction between the $\mathrm{OLC}$ and $\mathrm{M}_{2}$ muscarinic mechanism. Microinjection of 0.75 $\mu \mathrm{g}$ of the Fab fragments or $0.4 \mu \mathrm{g}$ of mAb T8B11 was performed to examine the possible actions of the OLC in the RVLM. The mAb was injected twice $(0.2 \mu \mathrm{g}$ each time) into the RVLM, 3 min apart. The concentration of the $\mathrm{mAb}(0.2 \mu \mathrm{g} / 50 \mathrm{nl})$ was chosen because its oncotic pressure was close to that of interstitial fluid. In addition, in a preliminary experiment, we noticed only a subtle effect when $0.2 \mu \mathrm{g}$ of mAb T8B11 was injected once, whereas substantial depressor and sympathoinhibitory effects were evoked with good reproducibility when the $\mathrm{mAb}$ was injected twice. In the series of experiments using the Fab fragments and $\mathrm{mAb}$ T8B11, microinjection of nonspecific $\mathrm{IgG}$ served as controls. Single injection of nonspecific IgG was done in seven rats and repeated injections of nonspecific $\mathrm{IgG}$ was done in four rats. To determine whether the cardiovascular effects of the OLC in the RVLM were mediated by a cholinergic mechanism, 2 nmol of gallamine was microinjected $(a)$ solely; $(b)$ after microinjection of $10 \mathrm{ng}$ of ouabain; or $(c)$ after microinjection of $0.75 \mu \mathrm{g}$ of the Fab fragment.

Furthermore, to know if the effects of blocking the OLC in the RVLM were observed only in rats anesthetized with urethane, the Fab fragments $(n=6)$ and nonspecific $\operatorname{IgG}(n=5)$ were microinjected into the unilateral RVLM of rats anesthetized with propofol (29-31), which is structurally unrelated to urethane. In these experiments, anesthesia was induced with intraperitoneal injection of sodium pentobarbital $(50 \mathrm{mg} / \mathrm{kg})$. Right femoral artery and bilateral femoral veins were cannulated for monitoring arterial pressure and drug administration, respectively. As the effects of the sodium pentobarbital began to disappear, propofol (Diprivan; ZENECA Pharmaceuticals, Osaka, Japan) was infused at a rate of $50 \mathrm{mg} / \mathrm{kg} / \mathrm{h}$ for surgical procedures and at a rate of $30 \mathrm{mg} / \mathrm{kg} / \mathrm{h}$ during the medullary microinjections. The remaining animal preparations and microinjection procedures were the same as in the urethane-anesthetized experiments.

Histological analysis. At the completion of each experiment, rats were intravenously given $50 \mathrm{mg}$ of pentobarbital sodium and then perfused transcardially with $150 \mathrm{ml}$ of $0.9 \%$ sodium chloride followed by $150 \mathrm{ml}$ of $10 \%$ phosphate-buffered formalin. The brainstem was removed, stored overnight in $10 \%$ phosphate-buffered formalin, and then transferred to a fixative containing $30 \%$ sucrose. Frozen brain tissue was sectioned in the coronal plane $(50 \mu \mathrm{m})$ and stained with neutral red. Microinjection sites were identified by the deposition of Alcian blue dye and referred to standard anatomical structures of the caudal brain stem according to the atlas of Paxinos and Watson (32).

Statistical analysis. Results are expressed as means \pm SEM. Comparisons between two observations in the same animal were assessed by the Student's paired $t$ test, and comparisons between two observa- 

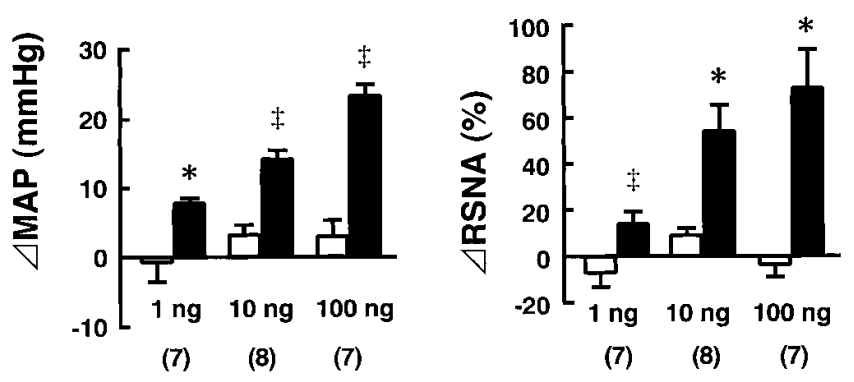

Figure 1. Changes in MAP and percentage changes in RSNA produced by microinjections of ouabain (1-100 ng, solid bars) or artificial CSF (open bars, control) into the unilateral RVLM. Microinjections of ouabain caused significant dose-dependent increases in MAP $(P<$ $0.001)$ and RSNA $(P<0.05)$ as shown by ANOVA. The numbers in parentheses represent the number of observations in each group. ${ }^{*} P<0.05,{ }^{\ddagger} P<0.01$, compared with their respective controls. Data represent mean \pm SEM.

tions from different animals were assessed by the unpaired $t$ test. Factorial experiments were analyzed by ANOVA. $P<0.05$ was considered to be statistically significant.

\section{Results}

Inhibition of $\mathrm{Na}^{+}, \mathrm{K}^{+}$-ATPase in the RVLM. The mean baseline value of MAP in rats used for the microinjection experiments was $87 \pm 2 \mathrm{mmHg}$. Microinjections of 1,10 , and $100 \mathrm{ng}$ of ouabain into the unilateral RVLM elicited increases in MAP and RSNA. The magnitude of the peak responses in MAP and RSNA were dose dependent (Fig. 1) whereas artificial CSF injected before the microinjection of each dose of ouabain had negligible effects (Fig. 1). Sites where microinjections of ouabain produced pressor and sympathoexcitatory responses were sites where injection of L-Glu also evoked increases in BP and RSNA. Fig. 2 shows a composite of the locations where both ouabain and L-Glu increased BP and RSNA. Pressor and sympathoexcitatory responses were produced by injection of ouabain in an area encompassing the dorsolateral aspect of the
Table I. Time Course of Pressor or Depressor Effect of Ouabain, Digoxin-specific Antibody Fab Fragments, and $m A b$ T8B11 Microinjected into the Unilateral RVLM

\begin{tabular}{lrcr}
\hline \multicolumn{1}{c}{ Drugs (dose) } & $n$ & Onset times & Response plateau \\
\hline Ouabain $(10 \mathrm{ng})$ & 8 & $13 \pm 3.3 \mathrm{~s}$ & $3 \pm 0.3 \mathrm{~min}$ \\
Fab fragments $(0.75 \mu \mathrm{g})$ & 10 & $3 \pm 0.5 \mathrm{~min}$ & $12 \pm 0.6 \mathrm{~min}$ \\
mAb T8B11 $(0.4 \mu \mathrm{g})$ & 8 & $5 \pm 0.2 \mathrm{~min}$ & $17 \pm 1.5 \mathrm{~min}$ \\
\hline
\end{tabular}

Data represent mean \pm SEM.

lateral paragigantocellular nucleus (LPGi) and a region dorsolateral to the LPGi. This area lies at the caudal end of the facial nucleus. The pressor responses produced by $10 \mathrm{ng}$ of ouabain occurred within at least $30 \mathrm{~s}$. The pressor and sympathoexcitatory responses evoked by $10 \mathrm{ng}$ of ouabain consistently lasted for at least 30 min (Fig. $3 a$ ). The onset times and response plateau of BP response to ouabain microinjection are summarized in Table I. Although peak responses to $100 \mathrm{ng}$ of ouabain were greater than those to smaller doses, two of the seven rats receiving $100 \mathrm{ng}$ of ouabain had long-lasting reductions in MAP and RSNA preceded by the initial pressor and sympathoexcitatory responses. Thus, the dose of ouabain was fixed to $10 \mathrm{ng}$ in experiments examining the interactions between ouabain and other drugs. Nonspecific inhibition of $\mathrm{Na}^{+}$, $\mathrm{K}^{+}$-ATPase by microinjection of melittin also elicited longlasting increases in MAP and RSNA, similar to the responses induced by ouabain (data not shown).

Ganglionic blockade by intravenous administration of hexamethonium abolished the pressor response induced by ouabain in the RVLM after returning MAP to baseline levels by the intravenous infusion of phenylephrine (Fig. $3 b$ ).

Microinjection of kainic acid into the RVLM promptly increased MAP by $20-40 \mathrm{mmHg}$, and then decreased MAP. Within $\sim 5 \mathrm{~min}$, MAP reached a minimum $(-8 \pm 3 \mathrm{mmHg}$ below baseline MAP, $n=5$ ) and stabilized for at least $5 \mathrm{~min}$. After that MAP gradually increased again and often exceeded baseline MAP. Since the increase in MAP evoked by the mi-

\section{Ouabain}

\section{Interaural}

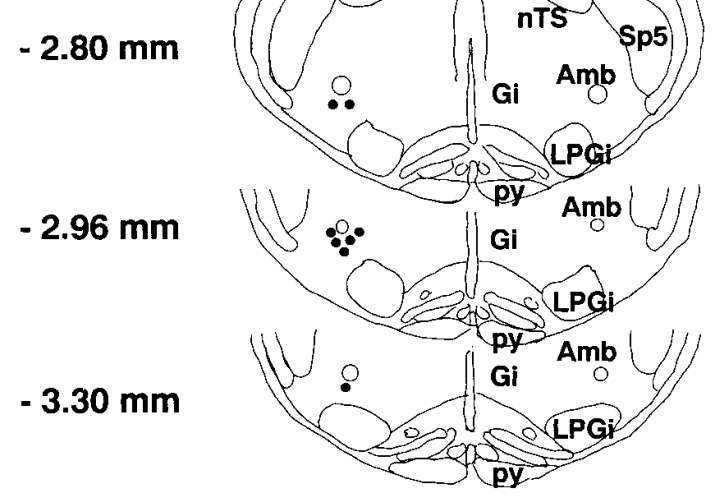

\section{Digoxin-specific antibody Fab fragments}

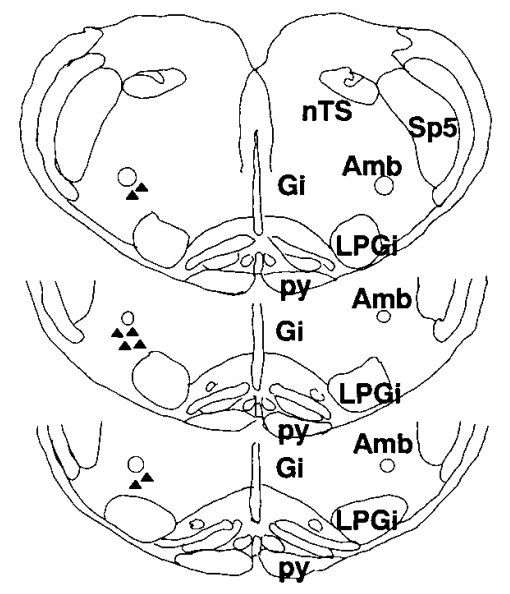

Figure 2. Injection sites of ouabain (solid circles, $n=8$ ) or digoxin-specific antibody Fab fragments (solid triangles, $n=8$ ) in ventrolateral medulla oblongata. Distances from interaural line are on the left side of the figure. $A m b$, nucleus ambiguous; $L P G i$, lateral paragigantocellular nucleus; $G i$, gigantocellular reticular nucleus; $p y$, pyramidal tract; $n T S$, nucleus tractus solitarius; $S p 5$, spinal trigeminal nucleus according to Paxinos and Watson (32). 

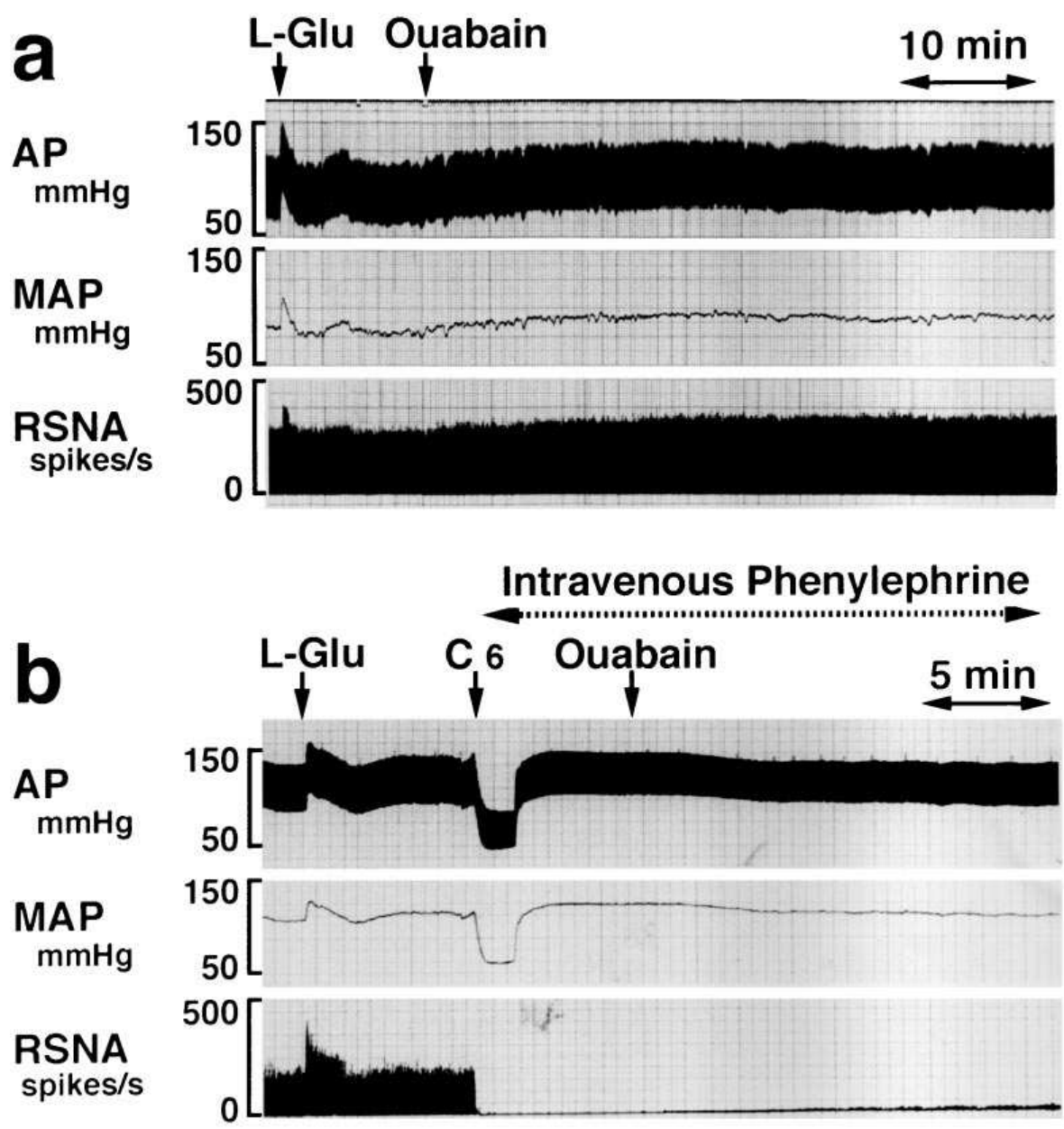

Figure 3. Traces of arterial pressure $(A P)$, MAP, and RSNA in response to microinjections of drugs into the unilateral RVLM. L-Glu (2 nmol) was microinjected to verify precise placement of the micropipette in the RVLM. (a) Microinjection of ouabain (10 ng) caused long-lasting increases in MAP and RSNA. (b) The pressor effect of ouabain (10 ng) was completely abolished after ganglion blockade by the intravenous administration of hexamethonium $(C 6,40 \mathrm{mg} / \mathrm{kg})$. Baseline MAP was maintained by continuous intravenous infusion of phenylephrine.

croinjection of $10 \mathrm{ng}$ of ouabain into the RVLM reached a plateau level within $5 \mathrm{~min}$, ouabain injection after pretreatment with kainic acid was performed 5 min after the first injection of the neurotoxin. Then the changes in MAP and RSNA from the minimum to the values $5 \mathrm{~min}$ after the ouabain injection

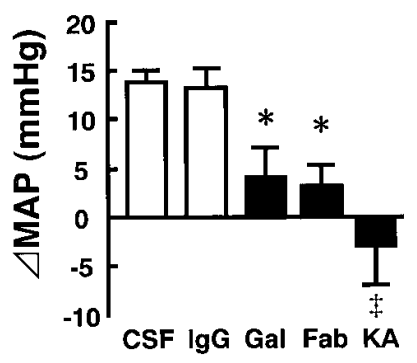

(8) (7) (8) (10) (5)

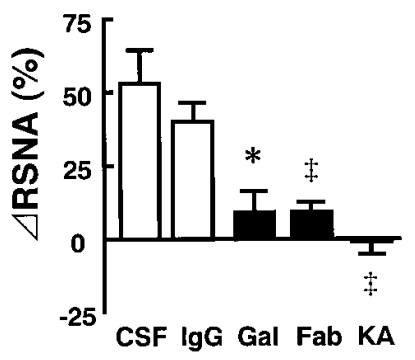

(8) (7) (8) (10) (5)
Figure 4. Changes in MAP and percentage changes in RSNA produced by the microinjection of ouabain $(10 \mathrm{ng})$ into the unilateral RVLM after pretreatment with gallamine ( $\mathrm{Gal}, 2 \mathrm{nmol})$, digoxinspecific antibody Fab fragments (Fab, $0.75 \mu \mathrm{g})$, kainic acid $(K A, 1$ nmol) (solid bars), or two controls (open bars); artificial CSF and nonspecific $\mathrm{IgG}$. The numbers in parentheses represent the number of observations in each group. ${ }^{*} P<0.05,{ }^{\ddagger} P<0.01$, compared with their respective controls. Data represent mean \pm SEM. were measured. Pretreatment of the RVLM with kainic acid totally blocked increases in MAP and RSNA induced by ouabain, whereas pretreatment with artificial CSF preserved the ouabain-induced responses (Fig. 4).

Prevention and reversal of the effects of exogenously administered ouabain by an $M_{2}$ muscarinic antagonist or digoxin-specific antibody Fab fragments. The pressor and sympathoexcitatory effects induced by microinjecting $10 \mathrm{ng}$ of ouabain into the RVLM were significantly attenuated by prior microinjections of $2 \mathrm{nmol}$ gallamine or $0.75 \mu \mathrm{g}$ of the Fab fragments, while pretreatment with $0.75 \mu \mathrm{g}$ of nonspecific $\mathrm{IgG}$ did not affect ouabain-induced increases in MAP and RSNA (Fig. 4). Furthermore, when gallamine was microinjected into the RVLM after the ouabain-induced pressor response reached a plateau level, MAP and RSNA began to decrease promptly within $30 \mathrm{~s}$ (Fig. 5 a). However, elevated BP and RSNA induced by the injection of ouabain began to decrease gradually $\sim 3$ min after the microinjection of the Fab fragments (Fig. 5b). The magnitude of MAP responses to L-Glu injection was not altered by local pretreatment with gallamine $(27 \pm 1 \mathrm{mmHg}$ before pretreatment and $30 \pm 4 \mathrm{mmHg}$ after pretreatment, $n=7$ ), the Fab fragments $(29 \pm 1 \mathrm{mmHg}$ before pretreatment and $29 \pm 3 \mathrm{mmHg}$ after pretreatment, $n=7)$, or mAb T8B11 $(26 \pm 1$ $\mathrm{mmHg}$ before pretreatment and $27 \pm 2 \mathrm{mmHg}$ after pretreatment, $n=8$ ). Thus gallamine, the Fab fragments, and $\mathrm{mAb}$ T8B11 did not exert local anesthetic action in the RVLM. 

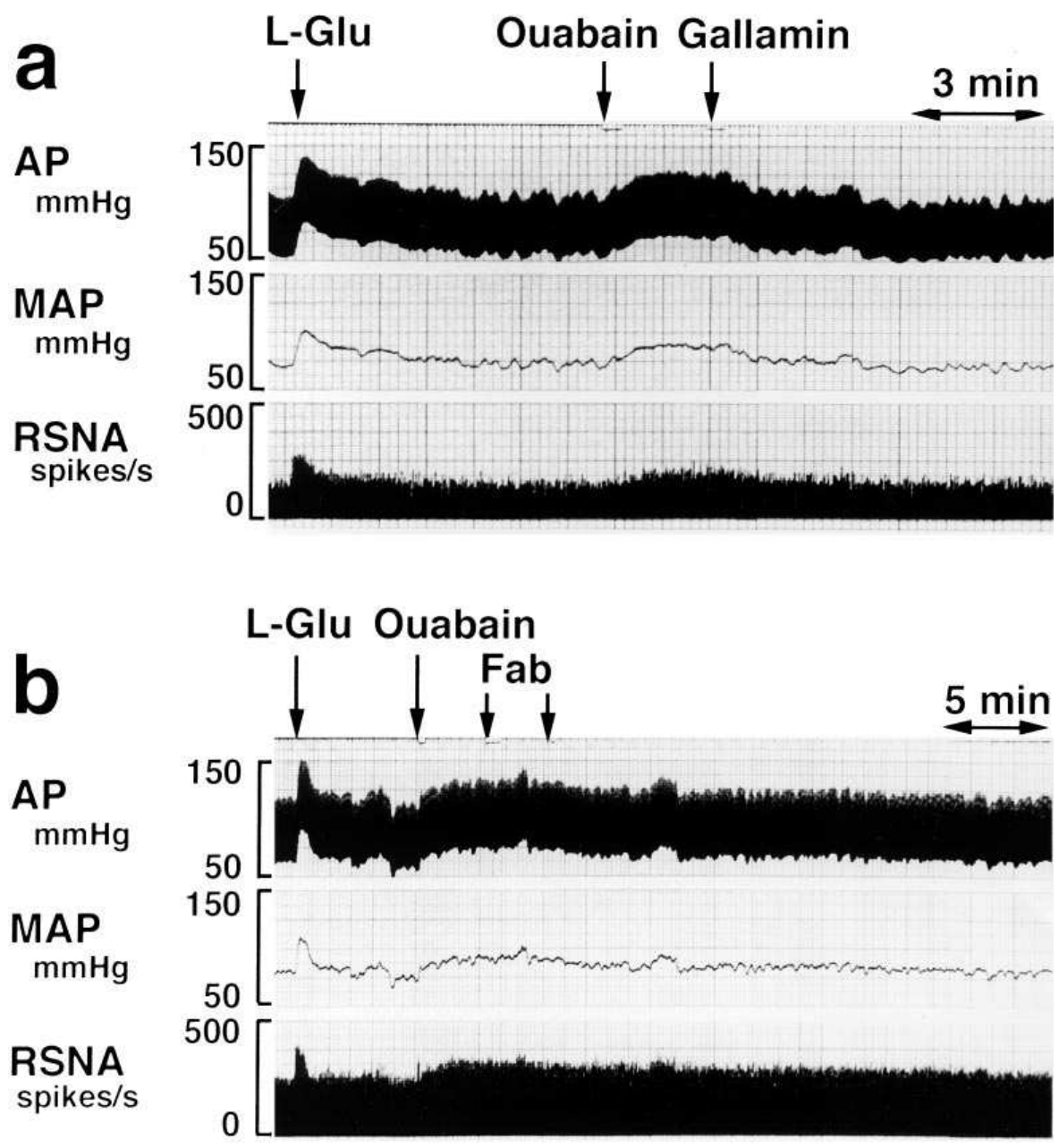

Figure 5. Traces of arterial pressure $(A P)$, MAP, and RSNA in response to microinjections of drugs into the unilateral RVLM. L-Glu ( $2 \mathrm{nmol}$ ) was microinjected to verify precise placement of the micropipette in the RVLM. (a) The effects of ouabain $(10 \mathrm{ng})$ were rapidly reversed by the microinjection of gallamine $(2 \mathrm{nmol}) .(b)$ The effects of ouabain (10 ng) were gradually reversed by the microinjection of 1.5 $\mu \mathrm{g}(0.75 \mu \mathrm{g} \times 2)$ of digoxin-specific antibody Fab fragments (Fab).

Effects of blocking the OLC in the RVLM, and interaction between the $\mathrm{OLC}$ and $M_{2}$ muscarinic mechanism. Microinjections of the Fab fragments per se significantly decreased MAP and RSNA ( $\triangle$ MAP: $-10 \pm 2 \mathrm{mmHg}, P<0.001, \% \Delta$ RSNA: $-18 \pm 3 \%, P<0.001, n=10)$, while nonspecific IgG did not ( $\Delta$ MAP: $2 \pm 2 \mathrm{mmHg}, \% \Delta$ RSNA: $7 \pm 4 \%, n=11$ ). Because the effects of single injection and repeated injections of nonspecific IgG were similar, we combined the data. Fig. 2 shows a composite of the locations where the Fab fragments produced depressor and sympathoinhibitory responses and L-Glu produced pressor and sympathoexcitatory responses. The Fab fragments caused decreases in BP and RSNA when injected in an area similar to that in which ouabain increased BP and RSNA. Microinjection of mAb T8B11 also significantly decreased MAP and RSNA ( $\triangle$ MAP: $-10 \pm 2 \mathrm{mmHg}, P<0.001$, $\% \Delta$ RSNA: $-14 \pm 3 \%, P<0.01, n=8)$ with a similar time course to that of the Fab fragments (Fig. 6). Table I summarizes the onset time and response plateau of the $\mathrm{BP}$ responses evoked by microinjections of the Fab fragments and $\mathrm{mAb}$ T8B11. The depressor and sympathoinhibitory effects of the Fab fragments and mAb T8B11 lasted for at least $30 \mathrm{~min}$. In the rats anesthetized with propofol, microinjections of the Fab fragments also significantly decreased MAP and RSNA ( $\triangle$ MAP: $-11 \pm 2$ mmHg, $P<0.01, \% \Delta$ RSNA: $-21 \pm 5 \%$, $P<0.05)$, while nonspecific IgG did not ( $\Delta$ MAP: $-2 \pm 2$ mmHg, $\% \Delta$ RSNA: $1 \pm 6 \%)$. The depressor and sympathoin- hibitory effects evoked by the Fab fragments lasted for at least $30 \mathrm{~min}$. The responses to microinjection of L-Glu were preserved after the delivery of the Fab fragments.

Microinjection of gallamine alone into the RVLM significantly decreased MAP and RSNA (Fig. 7, $a$ and $d$ ). Local pretreatment with ouabain in the RVLM significantly elevated the baseline MAP and RSNA, and enhanced the magnitude of depressor and sympathoinhibitory responses of gallamine (Fig. $7, b$ and $e$ ). Conversely, blockade of OLC in the RVLM with the Fab fragments significantly decreased the baseline MAP and RSNA, and attenuated the magnitude of gallamine-induced decreases in MAP and RSNA (Fig. 7, $c$ and $f$ ). Baseline MAP levels, MAP level or RSNA changes attained by microinjections of gallamine alone, gallamine after pretreatment with ouabain, and gallamine after pretreatment with the Fab fragments were similar among three groups (Fig. 7).

\section{Discussion}

In this study, ouabain microinjected into the RVLM acted as a sympathoexcitatory agent and increased BP and RSNA. Blockade of $\mathrm{M}_{2}$ muscarinic receptors with gallamine antagonized the actions of ouabain. Furthermore, blocking the actions of the OLC in the RVLM with digoxin-specific antibody Fab fragments or mAb T8B11 caused depressor and sympathoinhibitory responses in normotensive rats. Pretreatment 


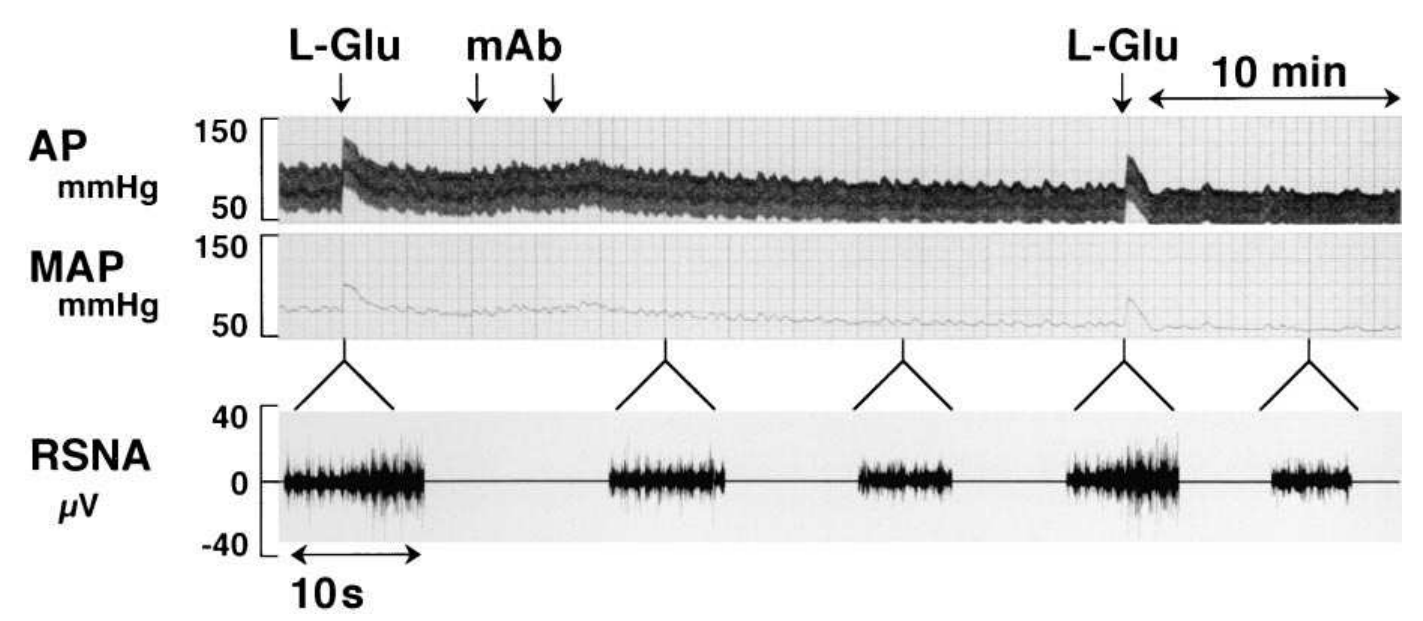

Figure 6. Traces of arterial pressure $(A P)$, MAP, and RSNA in response to microinjection of $0.4 \mu \mathrm{g}$ $(0.2 \mu \mathrm{g} \times 2)$ of $\mathrm{mAb}$ against ouabain into the unilateral RVLM. L-Glu (2 nmol) was microinjected to identify the precise placement of the micropipette in the RVLM, and to examine if the responsiveness of RVLM neurons was preserved after microinjection of the mAb. Note that the magnitude of the pressor response to L-Glu was similar between the L-Glu injections performed before and after the microinjection of the $\mathrm{mAb}$. with the Fab fragments also significantly attenuated the depressor and sympathoinhibitory effects of gallamine microinjected into the RVLM. These results suggest that the OLC in the RVLM contributes to the tonic activity of vasomotor neurons, and the actions of the OLC in the RVLM are at least partly mediated by $\mathrm{M}_{2}$ muscarinic mechanisms in anesthetized normotensive rats.

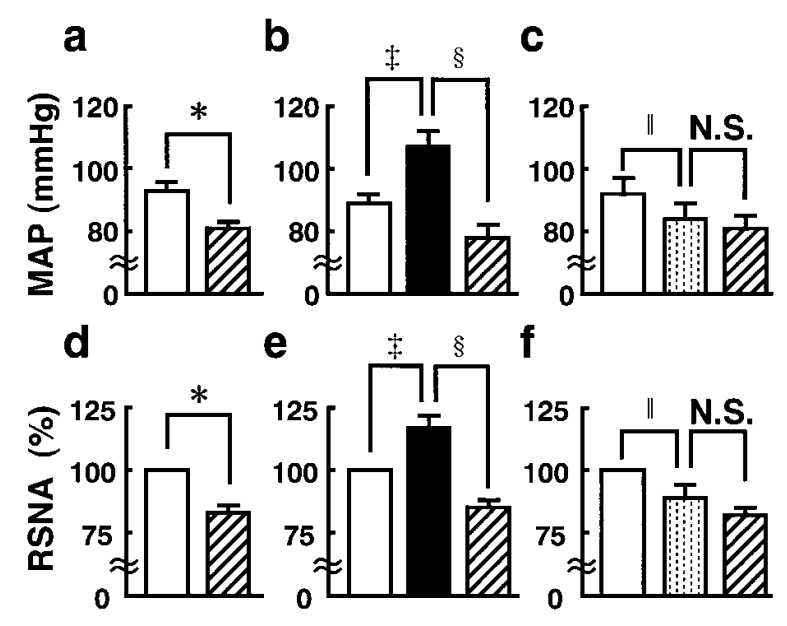

Figure 7. Baseline levels (open bars) of MAP and RSNA, and final levels (hatched bars) of MAP and RSNA produced by microinjections of $(a, d)$ gallamine alone $(2 \mathrm{nmol}, n=8),(b, e)$ gallamine after pretreatment with ouabain $(10 \mathrm{ng}, n=8)$, or $(c, f)$ gallamine after pretreatment with digoxin-specific antibody Fab fragments $(0.75 \mu \mathrm{g}$, $n=6$ ) into the unilateral RVLM. MAP and RSNA significantly decreased after microinjection of gallamine alone into the RVLM $\left({ }^{*} P<0.01\right)(a, d)$. MAP and RSNA significantly elevated after pretreatment with ouabain (solid bars) $\left({ }^{\ddagger} P<0.01\right)$, and significantly decreased when gallamine was microinjected after ouabain $\left({ }^{\S} P<0.01\right)$ $(b, e)$. MAP and RSNA significantly decreased after pretreatment with the Fab fragments (dotted bars) $\left({ }^{\mathbb{I l}} P<0.05\right)$, and both parameters did not show further decrease when gallamine was microinjected after the Fab fragments (N.S.) $(c, f)$. The baseline value of RSNA in each rat was designated as $100 \%$. Data represent mean \pm SEM.
Ouabain injected into the RVLM elicited dose-dependent increases in MAP and RSNA. This finding is in accordance with a previous report (33) in which microinjections of ouabain into the lateral reticular nucleus of cats caused a dosedependent pressor effect. Histological analysis of ouabainresponsive sites in the RVLM placed them in a region known as the ventrolateral pressor area (34), or subretrofacial nucleus (35). This region contains neurons which project to sympathetic preganglionic neurons of the intermediolateral cell column $(36,37)$. The effects of ouabain may be due to the inhibition of $\mathrm{Na}^{+}, \mathrm{K}^{+}$-ATPase in the RVLM, because nonspecific inhibition of $\mathrm{Na}^{+}, \mathrm{K}^{+}$-ATPase by melittin, an amphipathic helical polypeptide (38), caused similar effects. Although microinjection of $100 \mathrm{ng}$ of ouabain elicited depressor and sympathoinhibitory responses preceded by initial pressor and sympathoexcitatory responses in two out of seven rats, these responses were probably attributable to profound disturbances in the ionic homeostasis (39) or the neuronal toxicity of ouabain (40). The pressor response induced by ouabain was derived through stimulation of sympathetic efferent activity because ganglionic blockade abolished the pressor response induced by ouabain in the RVLM. The actions of ouabain in the RVLM required intact cell bodies in this region, and were not attributed to stimulation of fiber in the passage. This is based on the observation that pretreating the RVLM with kainic acid totally blocked increases in MAP and RSNA induced by the microinjection of ouabain. Kainic acid is thought to selectively antagonize synaptic transmission by depolarizing the neuronal cell body (25) without affecting axonal conduction (41).

Acetylcholine acts on $\mathrm{M}_{2}$ muscarinic receptors in the RVLM to exert a pressor response $(18,19)$. Microinjection of gallamine, an $\mathrm{M}_{2}$ muscarinic antagonist, successfully prevented or reversed the pressor and sympathoexcitatory responses induced by ouabain in the RVLM, while responses to L-Glu were preserved after the delivery of gallamine. Furthermore, the depressor and sympathoinhibitory effects of gallamine were enhanced by a prior injection of ouabain into the RVLM, whereas the effects of gallamine were attenuated by a prior in- 
jection of the Fab fragments. These results suggest that the effects of ouabain and the OLC in the RVLM are at least partly mediated by $\mathrm{M}_{2}$ muscarinic mechanisms. Cardiac glycosides including ouabain enhance the release of acetylcholine from parasympathetic nerve endings (42). In the brain, ouabain was reported to induce the release of acetylcholine from cortical synaptosomes in vitro (20-22). Because acetylcholine is thought to inhibit local inhibitory neurons in the RVLM (43), we speculate that the sympathoexcitatory actions of ouabain in the RVLM could be attributable to increased acetylcholine release which in turn results in an inhibition of an inhibitory input to the vasomotor neurons. In support of this speculation, a preliminary ultrastructural study demonstrated that the majority of synaptic contacts made by cholinergic terminals on RVLM neurons appear to be of the inhibitory type (44). However, the possibility that ouabain in the RVLM directly stimulates postsynaptic receptor sites or postreceptor mechanisms cannot be overlooked.

In this study, the Fab fragments antagonized the pressor and sympathoexcitatory effects of ouabain microinjected into the RVLM. Furthermore, microinjection of the Fab fragments or mAb T8B11 into the RVLM significantly decreased baseline MAP and RSNA. Because the depressor and sympathoinhibitory effects of blocking the OLC in the RVLM were observed in rats anesthetized with both urethane and with propofol, these effects were not specific for certain anesthesia. Histological examination revealed clear overlap of sites where microinjections of the Fab fragments produced depressor and sympathoinhibitory responses and sites where microinjection of ouabain evoked increases in BP and RSNA. However, microinjection of nonspecific IgG into the RVLM did not affect baseline MAP or RSNA, nor responses to subsequent microinjections of ouabain. Also, microinjections of nonspecific Fab fragments into the RVLM did not affect baseline MAP and RSNA (our unpublished observation). The mAb T8B11, which recognizes the pharmacologically active portion of ouabain and cross-reacts with ouabain-like $\mathrm{K}^{+}$-rival type $\mathrm{Na}^{+}, \mathrm{K}^{+}$ATPase inhibitory substances consisting of the cis-linked D ring and the functional groups at positions C13, C14, and C17 (45), is subclassified as murine IgG2b kappa and neutralizes the biological activity of ouabain. The mAb T8B11 does not cross-react with classic adrenocortical steroids, sex steroids, or other $\mathrm{K}^{+}$-nonrival type $\mathrm{Na}^{+}, \mathrm{K}^{+}$-ATPase inhibitory substances such as mAb 249F8 and 278A9 (45). Our results clearly suggest that the OLC existing in the rat RVLM contributes to the ongoing activity of the local vasomotor neurons. The action of OLC in the RVLM is also likely to be mediated by the local $\mathrm{M}_{2}$ muscarinic receptors, because blockade of OLC in the RVLM with the Fab fragments attenuated the magnitude of gallamine-induced changes in MAP and RSNA. Our results are consistent with a notion that acetylcholine is tonically released in the RVLM (17).

Ouabain inhibits $\mathrm{Na}^{+}, \mathrm{K}^{+}$-ATPase activity by binding to its $\alpha$ subunit. Among three isoforms of $\alpha$ subunit of $\mathrm{Na}^{+}, \mathrm{K}^{+}$ATPase, $\alpha_{3}$ isoform, which has about a 1,000-fold higher affinity for ouabain than $\alpha_{1}$ isoform irrespective of isoforms of $\beta$ subunit of this enzyme (46), is a predominant type in the brain tissue, and local expression of $\alpha_{3}$ mRNA is much more abundant than that of $\alpha_{1}$ mRNA in the brainstem (47). Therefore, it is conceivable that the OLC acts in the medulla oblongata where the high-affinity isoform of $\mathrm{Na}^{+}, \mathrm{K}^{+}$-ATPase is abundant.
The time of the onset of the effects of the Fab fragments in the RVLM was similar to those of the reversal of digitalis effects by the Fab fragments in isolated cardiac muscle, that is, effects occurred within minutes (48). However, reversal of the effects of the digitalis-like factor, ouabain, or digitalis in erythrocytes has a longer latency, that is, effects occurred within hours $(26,48)$. We do not know the precise reason why the time course of the effects of the Fab fragments differed among the RVLM neurons, isolated cardiac muscles, and erythrocytes. But it may be related to differences in their affinity constants, or in their dissociation rate constants, presumably due to differences in the $\alpha$ isoforms of $\mathrm{Na}^{+}, \mathrm{K}^{+}$-ATPase in these tissues. Erythrocyte precursors only express $\alpha_{1}$ mRNA (49), while neural and myocardial tissues express all three $\alpha$ isoforms (50).

In summary, ouabain microinjected into the RVLM elicited hypertensinogenic effects through sympathetic activation in anesthetized normotensive rats. Integrity of the RVLM neurons was required for the effects of ouabain. Blockade of the actions of the OLC in the RVLM neurons by digoxin-specific antibody Fab fragments or mAb against ouabain caused depressor and sympathoinhibitory responses without nonspecific depression of RVLM neurons. $\mathrm{M}_{2}$ muscarinic blockade antagonized the effects of ouabain and the OLC. These findings suggest that the OLC in the RVLM contributes to the tonic activity of vasomotor neurons in normotensive rats, and the actions of the OLC in the RVLM are at least partly mediated by $\mathrm{M}_{2}$ muscarinic mechanisms. Studies under conscious unrestrained state are needed to further elucidate whether the OLC in the RVLM has a role in physiological conditions as well as certain pathological conditions.

\section{Acknowledgments}

We thank Rijiko Matayoshi for her technical assistance. We thank ZENECA Pharmaceuticals for their kind gift of propofol.

\section{References}

1. Goto, A., K. Yamada, N. Yagi, M. Yoshioka, and T. Sugimoto. 1992. Physiology and pharmacology of endogenous digitalis-like factors. Pharmacol. Rev. 44:377-399.

2. Doris, P.A. 1994. Regulation of Na,K-ATPase by endogenous ouabainlike materials. PSEBM (Proc. Soc. Exp. Biol. Med.). 205:202-212.

3. Woolfson, R.G., L. Poston, and H.E. de Wardener. 1994. Digoxin-like inhibitors of active sodium transport and blood pressure: the current status. Kidney Int. 46:297-309.

4. Ludens, J.H., M.A. Clark, D.W. DuCharme, D.W. Harris, B.S. Lutzke, F. Mandel, W.R. Mathews, D.M. Sutter, and J.M. Hamlyn. 1991. Purification of an endogenous digitalislike factor from human plasma for structural analysis. $\mathrm{Hy}$ pertension (Dallas). 17:923-929.

5. Tymiak, A.A., J.A. Norman, M. Bolgar, G.C. DiDonato, H. Lee, W.L. Parker, L.-C. Lo, N. Berova, K. Nakanishi, E. Haber, and G.T. Haupert, Jr. 1993. Physicochemical characterization of a ouabain isomer isolated from bovine hypothalamus. Proc. Natl. Acad. Sci. USA. 90:8189-8193.

6. Zhao, N., L.-C. Lo, N. Berova, K. Nakanishi, A.A. Tymiak, J.M. Ludens, and G.T. Haupert, Jr. 1995. Na,K-ATPase inhibitors from bovine hypothalamus and human plasma are different from ouabain: nanogram scale CD structural analysis. Biochemistry. 34:9893-9896.

7. Hallaq, H.A., and G.T. Haupert, Jr. 1989. Positive inotropic effects of the endogenous $\mathrm{Na}^{+} / \mathrm{K}^{+}$-transporting ATPase inhibitor from the hypothalamus. Proc. Natl. Acad. Sci. USA. 86:10080-10084.

8. Bova, S., M.P. Blaustein, J.H. Ludens, D.W. Harris, D.W. DuCharma, and J.M. Hamlyn. 1991. Effects of an endogenous ouabainlike compound on heart and aorta. Hypertension (Dallas). 17:944-950.

9. Weiss, D.N., D.J. Podberesky, J. Heidrich, and M.P. Blaustein. 1993. Nanomolar ouabain augments caffeine-evoked concentrations in rat arteries. Am. J. Physiol. 265:C1443-C1448.

10. Huang, B.S., X. Huang, E. Harmsen, and F.H.H. Leenen. 1994. Chronic central versus peripheral ouabain, blood pressure, and sympathetic activity in 
rats. Hypertension (Dallas). 23:1087-1090.

11. Huang, B.S., and F.H.H. Leenen. 1995. Brain 'ouabain,' sodium, and arterial baroreflex in spontaneously hypertensive rats. Hypertension (Dallas). 25: 814-817.

12. Huang, B.S., and F.H.H. Leenen. 1995. Brain 'ouabain' and desensitization of arterial baroreflex by high sodium in Dahl salt-sensitive rats. Hypertension (Dallas). 25:372-376.

13. Takahashi, H., N. Ihara, Y. Terano, H. Yamada, M. Nishimura, T. Nakanishi, K. Yamamoto, Y. Kinoshita, and M. Yoshimura. 1994. Ouabain-like immunoreactive substances exist in the hypothalamus and the adrenal medulla in rats. Pathophysiology. 1:25-28.

14. Teruya, H., H. Muratani, R. Matayoshi, S. Takishita, A. Sakima, M. Yamazato, and K. Fukiyama. 1996. Ouabain-like factor contributes to the tonic activity of vasomotor neurons in the rostral ventrolateral medulla. J. Hypertens. 14(Suppl. 1):S152a. (Abstr.)

15. Brown, D.L., and P.G. Guyenet. 1985. Electrophysiological study of cardiovascular neurons in the rostral ventrolateral medulla in rats. Circ. Res. 56: 359-369.

16. Ciriello, J., M.M. Caverson, and C. Polosa. 1986. Function of the ventrolateral medulla in the control of the circulation. Brain Res. Rev. 11:359-391.

17. Dampney, R.A.L. 1994. Functional organization of central pathways regulating the cardiovascular system. Physiol. Rev. 74:323-364.

18. Arneric, S.P., R. Giuliano, P. Ernsberger, M.D. Underwood, and D.J. Reis. 1990. Synthesis, release and receptor binding of acetylcholine in the C1 area of the rostral ventrolateral medulla: contributions in regulating arterial pressure. Brain Res. 511:98-112.

19. Sundaram, K., A.J. Krieger, and H. Sapru. 1988. $\mathbf{M}_{2}$ muscarinic receptors mediate pressor responses to cholinergic agonists in the ventrolateral medullary pressor area. Brain Res. 449:141-149.

20. Vizi, E.S. 1972. Stimulation, by inhibition of $\left(\mathrm{Na}^{+}-\mathrm{K}^{+}-\mathrm{Mg}^{2+}\right)$-activated ATP-ase, of acetylcholine release in cortical slices from rat brain. J. Physiol. (Lond.). 226:95-117.

21. Meyer, E.M., and J.R. Cooper. 1981. Correlations between $\mathrm{Na}^{+}, \mathrm{K}^{+}$ATPase activity and acetylcholine release in rat cortical synaptosomes. J. Neurochem. 36:467-475.

22. Satoh, E., and Y. Nakazato. 1992. On the mechanism of ouabain-induced release of acetylcholine from synaptosomes. J. Neurochem. 58:1038-1044.

23. Muratani, H., D.B. Averill, and C.M. Ferrario. 1991. Effect of angiotensin II in ventrolateral medulla of spontaneously hypertensive rats. Am. J. Physiol. 260:R977-R984.

24. Sesoko, S., H. Muratani, S. Takishita, H. Teruya, N. Kawazoe, and K. Fukiyama. 1995. Modulation of baroreflex function by angiotensin II endogenous to the caudal ventrolateral medulla. Brain Res. 671:38-44.

25. Olney, J.W., V. Rhee, and O.L. Ho. 1974. Kainic acid: a powerful neurotoxic analogue of glutamate. Brain Res. 77:507-512.

26. Balzan, S., U. Montali, P. Biver, and S. Ghione. 1991. Digoxin-binding antibodies reverse the effect of endogenous digitalis-like compounds on $\mathrm{Na}, \mathrm{K}$ ATPase in erythrocytes. J. Hypertens. 9(Suppl. 6):S304-S305.

27. Huang, B.S., E. Harmsen, H. Yu, and F.H.H. Leenen. 1992. Brain ouabain-like activity and the sympathoexcitatory and pressor effects of central sodium in rats. Cir. Res. 71:1059-1066.

28. Michel, A.D., R.E. Delmendo, M. Lopez, and R.L. Whiting. 1990. On the interaction of gallamine with muscarinic receptor subtypes. Eur. J. Pharmacol. 182:335-345.

29. Krassioukov, A.V., A.W. Gelb, and L.C. Weaver. 1993. Action of propofol on central sympathetic mechanisms controlling blood pressure. Can. J. Anaesth. 40:761-769.

30. Krassioukov, A.V., and L.C. Weaver. 1993. Connections between the pontine reticular formation and rostral ventrolateral medulla. Am. J. Physiol.
265: H1386-H1392.

31. Butcher, K.S., and D.F. Cechetto. 1995. Autonomic responses of the insular cortex in hypertensive and normotensive rats. Am. J. Physiol. 268:R214$\mathrm{R} 222$

32. Paxinos, G., and C. Watson. 1986. The Rat Brain in Stereotaxic Coordinates. Academic Press, New York.

33. Bousquet, P., J. Feldman, and J. Schwartz. 1984. The effects of ouabain in the medullary site of the hypotensive action of clonidine. Life Sci. 35:373380

34. Willette, R.N., P.P. Barcas, A.J. Krieger, and H.N. Sapru. 1983. Vasopressor and depressor areas in the rat medulla. Identification by microinjection of L-glutamate. Neuropharmacology. 22:1071-1079.

35. Dampney, R.A.L., and R.M. McAllen. 1987. Vasomotor control by subretrofacial neurons in the rostral ventrolateral medulla. Can. J. Physiol. Pharmacol. 65:1572-1579.

36. Ross, C.A., D.A. Ruggiero, T.H. Joh, D.H. Park, and D.J. Reis. 1984 Rostral ventrolateral medulla: selective projection to the thoracic autonomic cell column from the region containing $\mathrm{C} 1$ adrenaline neurons. J. Comp. Neurol. 228:168-185.

37. Dampney, R.A.L., J. Czachurski, K. Dembowsky, A.K. Goodchild, and H. Seller. 1987. Afferent connection and spinal projections of the pressor region in the rostral ventrolateral medulla of the cat. J. Auton. Nerv. Syst. 20:7386.

38. Cuppoletti, J., and A.J. Abbott. 1990. Interaction of melittin with the $\left(\mathrm{Na}^{+}+\mathrm{K}^{+}\right)$ATPase: evidence for a melittin-induced conformational change. Arch. Biochem. Biophys. 283:249-257.

39. Pumain, R., and U. Heinemann. 1985. Stimulus- and amino acid-induced calcium and potassium changes in rat neocortex. J. Neurophysiol (Bethesda). $53: 1-16$

40. Lees, G.J., and W. Leong. 1994. Brain lesions induced by specific and non-specific inhibitors of sodium-potassium ATPase. Brain Res. 649:225-233.

41. Curtis, D.R., and J.M. Crawford. 1969. Central synaptic transmission: microelectrophoretic studies. Annu. Rev. Pharmacol. 9:209-240.

42. Gillis, R.A., and J.A. Quest. 1980. The role of the nervous system in the cardiovascular effects of digitalis. Pharmacol. Rev. 31:19-97.

43. Giuliano, R., D.A. Ruggiero, S. Morrison, P. Ernsberger, and D.J. Reis 1989. Cholinergic regulation of arterial pressure by the $\mathrm{C} 1$ area of the rostral ventrolateral medulla. J. Neurosci. 9:923-942.

44. Milner, T.A., V.M. Pickel, C. Abate, and D.J. Reis. 1987. Choline acetyltransferase in the rat rostral ventrolateral medulla: ultrastructural localization and synaptic interactions with neurons containing catecholamine synthesizing enzymes. Society for Neuroscience Abstracts. 13:808a. (Abstr.)

45. Terano, Y., A. Tomii, and F. Masugi. 1991. Production and characterization of antibodies to ouabain. Jpn. J. Med. Sci. Biol. 44:123-139.

46. Blanco, G., G. Sanchez, and R.W. Mercer. 1995. Comparison of the enzymatic properties of the $\mathrm{Na}, \mathrm{K}-\mathrm{ATPase} \alpha 3 \beta 1$ and $\alpha 3 \beta 2$ isozymes. Biochemis try. 34:9897-9903.

47. Albers, R.W., G.J. Siegel, and W.L. Stahl. 1994. Membrane transport. In Basic Neurochemistry. G.J. Siegel, B.W. Agranoff, R.W. Albers, and P.B. Molinoff, editors. Raven Press, New York. 49-73.

48. Curd, J., T.W. Smith, J.-C. Jaton, and E. Haber. 1971. The isolation of digoxin-specific antibody and its use in reversing the effects of digoxin. Proc. Natl. Acad. Sci. USA. 68: 2401-2406.

49. Dhir, R., Y. Nishioka, and R. Blostein. 1990. Na,K-ATPase isoform expression in sheep red blood cell precursors. Biochim. Biophys. Acta. 1026:141146

50. Herrera, V.L.M., A.V. Chobanian, and N. Ruiz-Opazo. 1988. Isoformspecific modulation of $\mathrm{Na}^{+}, \mathrm{K}^{+}$-ATPase $\alpha$-subunit gene expression in hypertension. Science (Wash. DC). 241:221-223. 